\title{
Crescimento de Empresas na Perspectiva de Pequenos Empreendedores de Base Tecnológica
}

\author{
Growth of Companies from the Perspective of Small Technology-Based \\ Entrepreneurs
}

Hilka Pelizza Vier Machado ${ }^{1}$

https://orcid.org/0000-0002-2554-0025

Universidade do Oeste de Santa Catarina, Doutorado em Administração, Chapecó, SC, Brasil e Centro Universitário de Maringá, Mestrado em Gestão do Conhecimento, Maringá, PR, Brasil ${ }^{1}$ 


\title{
Resumo
}

O crescimento pode ser analisado sob diferentes níveis: ambiente, empresa e empreendedor. No nível do empreendedor, são escassas as pesquisas anteriores que abordaram percepções de empreendedores sobre dificuldades e determinantes de crescimento, as quais podem influenciar intenções e estratégias de crescimento. Esta pesquisa teve por objetivo compreender o processo do crescimento de empresas de base tecnológica, na perspectiva de empreendedores, focando determinantes e dificuldades de crescimento. Realizou-se uma pesquisa qualitativa com seis empreendedores, utilizando entrevistas abertas, que foram transcritas e codificadas com suporte do software N Vivo versão 9. As determinantes de crescimento para os empreendedores abrangem ações deles, da gestão das empresas e do ambiente. As dificuldades de crescimento foram mencionadas apenas no nível da gestão e do ambiente. Os resultados evidenciam a importância de percepções do empreendedor na compreensão do processo de crescimento, enquanto fenômeno multidimensional. Os resultados oferecem subsídios para formulação de políticas voltadas ao crescimento de pequenas e médias empresas de software.

Palavras-chave: empresas de base tecnológica; crescimento de empresas; empresas de software; empreendedores de base tecnológica.

\begin{abstract}
Growth can be analyzed in different levels: environment, company, and entrepreneur. At the entrepreneur level, few studies address the entrepreneurs' perceptions of difficulties and determinants of growth, whichcan influence intentions and growth strategies. This research aimed to understand the growth process of technology-based companies from the perspective of entrepreneurs, focusing on determinants and difficulties of growth. We conducted a qualitative research with six entrepreneurs using open-ended interviews, which were transcribed and encoded using N Vivo software version 9. The determinants of growth for entrepreneurs cover their actions, business management, and the environment. The entrepreneurs only mentioned difficulties with growth at the level of management and environment. The results show the importance of entrepreneur perceptions to understand the growth process as a multidimensional phenomenon. The results provide subsidies for the formulation of policies for the growth of small and medium-sized software companies.
\end{abstract}

Keywords: technology-based enterprises; business growth; software business; technology-based entrepreneurs.

JEL Codes: L26, O14, F43. 


\section{Introdução}

O crescimento de empresas é um tema que pode ser estudado sob diferentes perspectivas. Em geral, as pesquisas tendem a enfatizá-lo como sinônimo de mudança em quantidade e o consideram como variável dependente, com foco no resultado (Leitch, Hill, \& Harrison, 2010). Essas pesquisas mostram quanto as empresas cresceram, mas negligenciam outros aspectos voltados para explicar como e por que empresas cresceram (McKelvie \& Wiklund, 2010). Para compreender estes dois aspectos é importante considerar que o crescimento não apresenta necessariamente uma trajetória linear e homogênea (Davidsson, Achtenhagen, \& Naldi, 2010; Mckelvie \& Wiklund, 2010).

O crescimento pode variar de acordo com o tamanho da empresa. Empresas pequenas e médias tendem a crescer mais do que as grandes (Hamilton, 2012). O crescimento para empresas pequenas é complexo e requer a superação de incertezas, assim como o enfrentamento de riscos comerciais e tecnológicos (Penrose, 2006), tendo em vista que elas são mais vulneráveis às incertezas, taxas e variações do ambiente macroeconômico (Organisation for Economic Co-operation and Development [OCDE], 1998).

Além disso, a dinâmica do crescimento pode variar de acordo com o tipo de empresa. No caso de empresas de base tecnológica, compreendidas como "empresas independentes cuja base de negócios é desenvolver, comercializar ou manufaturar tecnologia" (Rannikko, 2012, p. 9), o crescimento está associado a especificidades dessas empresas, como o estabelecimento de cooperações com universidades (Moretti \& Crnkovic, 2015; Tumelero, Marins, Santos, \& Carnaúba, 2015) e a valorização do conhecimento. Além disso, algumas dessas empresas crescem mais e outras menos, e algumas crescem rapidamente e são denominadas gazelas (Achtenhagen, Naldi, \& Melin, 2010).

Entre pequenas empresas de base tecnológica, encontram-se as de software e de Tecnologia de informação (TI). No Brasil, de acordo com dados da Associação Brasileira de Empresas de Software (ABES, 2016), as empresas de TI, inserindo-se as de hardware, software e serviços, movimentaram 60 bilhões de dólares em 2015, representando 3,3 \% do PIB brasileiro. Aproximadamente 13.950 empresas dedicam-se ao desenvolvimento, produção e distribuição de software e de prestação de serviços. $\mathrm{O}$ crescimento é importante para essas empresas porque elas enfrentam, atualmente, um dinamismo do setor e competitividade com grandes empresas (Santos \& Pinho, 2010). Diante disso, esse setor foi escolhido para a realização desta pesquisa.

O crescimento pode ser analisado nos níveis macro, intermediário e individual. No nível individual, estudos têm mostrado a importância do empreendedor na promoção do crescimento da empresa, por meio de motivações, intenções e expectativas de crescimento (Lasch, Le Roy, \& Yami, 2007; Rasmussen, Ladegard, \& Korhonen-Sande, 2016). No entanto, intenções representam apenas a primeira etapa do processo de crescimento (Zampetakis, Bakatsaki, Kafetsios \& Moustakis, 2016). Como o empreendedor exerce um papel central no processo de crescimento (Rasmussen et al., 2016), há outros aspectos, além dos motivacionais, que podem influenciar o crescimento de negócios. Por exemplo, a experiência e o aprendizado podem contribuir para melhor compreensão acerca de determinantes e dificuldades de crescimento. Entende-se por determinantes de crescimento, os fatores que podem influenciar favoravelmente o crescimento e, que, segundo Wiklund, Patzelt e Shepherd (2009), podem ser associados ao indivíduo, à empresa ou ao ambiente. Dificuldades de crescimento representam "fatores internos e externos, ou as condições que limitam o potencial de crescimento de uma empresa que deseja crescer" (Storey, 1994, p. 155).

Diante do exposto, esta pesquisa ${ }^{(1)}$ buscou responder à questão: $\mathrm{O}$ que determina e o que dificulta o crescimento de empresas de base tecnológica na visão de empreendedores? O objetivo da pesquisa foi compreender o processo de crescimento para pequenos empreendedores de base tecnológica, focando determinantes e dificuldades. A pesquisa foi realizada junto a seis pequenos empreendedores do setor de software, cujas empresas são localizadas nos estados do Paraná e de Santa Catarina, no sul do Brasil. 
A estrutura do artigo inicia-se com o referencial teórico sobre crescimento de pequenas empresas, abrangendo determinantes e dificuldades de crescimento. Em seguida, foram descritos os procedimentos metodológicos utilizados na pesquisa e, posteriormente, foram apresentados os resultados e as respectivas análises.

\section{Crescimento de Pequenas Empresas}

O crescimento da empresa pode ser compreendido como "uma mudança no tamanho em um determinado período de tempo" (Dobbs \& Hamilton, 2007, p. 313). Para Penrose (2006), o crescimento reflete o desenvolvimento interno da empresa. Ele é derivado da avaliação que o empreendedor faz da empresa e do mercado, que se encontra em constante construção e reconstrução. O crescimento da empresa é representado pela variação positiva entre (pelo menos) dois pontos no tempo (Penrose, 2006). Esta variação pode estar associada a aumento nas vendas, no número de empregados, número de clientes, número de produtos ou serviços, entre outros (Brush, Ceru, \& Blackburn, 2009; Janssen, 2009). Segundo Janssen (2009), o que reflete o crescimento da empresa é o aumento na demanda pelos produtos ou serviços ofertados pela empresa, que consequentemente resultará no aumento das vendas, o que, por sua vez, poderá ser acompanhado de investimentos em fatores adicionais de produção. Outras concepções de crescimento, apresentadas por Achtenhagen, Naldi e Melin (2010), consideram que o crescimento pode ser também observado pelo aumento da lucratividade, aumento do valor da empresa, crescimento dos ativos e desenvolvimento de competências internas.

A mensuração do crescimento pode ocorrer de formas diferentes. O aumento nas vendas, no número de empregados ou na lucratividade são as formas mais discutidas na literatura (Janssen, 2009). Achtenhagen et al. (2010) consideram outras formas de mensuração, tais como crescimento dos ativos, crescimento do aumento do valor da empresa e desenvolvimento interno. Este último, para os autores, é refletido no desenvolvimento de competências, no estabelecimento de práticas organizacionais de eficiência e de profissionalização. O crescimento pode ainda ser interpretado como aumento do número de filiais, aumento de mercados, aumento do número de clientes ou aumento do número de produtos ou serviços (Brush et al., 2009).

Diferentes enfoques foram utilizados por pesquisadores para explicar o crescimento de pequenas empresas. O enfoque do ciclo de vida consiste em descrever o crescimento como um processo gradual, por meio de ciclos que se caracterizam por mudanças nos produtos, no mercado e na forma de gestão da empresa, e que ocorrerem em determinada sequência. Outro enfoque é centrado na forma de gestão, sendo o crescimento de pequenas empresas relacionado à competência de planejamento e gestão. Outra explicação do crescimento de empresas é como resultante de aspectos psicológicos, como intenções de crescimento (Rasmussen et al., 2016). Além disso, para esse enfoque, o crescimento pode ser resultante de outros motivos, como a necessidade de se sentir respeitado pela comunidade (Orser, Riding, \& Manley, 2006). Por fim, o enfoque dos estudos integrativos, considera que para compreender o crescimento é necessária uma abordagem de um processo multidisciplinar, abrangendo características de empreendedores, gestão das empresas e o ambiente (Orser et al., 2006; Sarwoko \& Frisdiantara, 2016).

O crescimento, enquanto um processo, é resultante de diversas ações e do desempenho de atores, na medida em que ele não é apenas o resultado do esforço do empreendedor, mas abrange também o apoio de outras pessoas, como clientes, familiares, fornecedores, entre outros (Leitch et al., 2010). Além de representar o resultado de um esforço coletivo, o crescimento resulta de condições que o determinam e de dificuldades que foram superadas (Levie \& Lichestein, 2010).

Para empresas de base tecnológica, o crescimento, segundo Davidsson, Achtenhagen e Naldi (2010), pode ter o significado de diversificação, de combinação produto-mercado, de entrada em novo mercado ou, ainda, um crescimento vertical, caracterizado pela integração na cadeia de valor. Para essas empresas, segundo os autores, o crescimento pode ser obtido por meio da adoção de uma tecnologia com a qual a empresa não operava, o que eles denominam de diversificação não relacionada. Contudo,

RAC, Rio de Janeiro, v. 22, n. 6, art. 1, pp. 817-840, novembro/dezembro, 2018, http://rac.anpad.org.br (cc) E 
o crescimento para essas empresas é um fator crítico devido ao grande risco de fracasso que elas enfrentam (Lasch et al., 2007).

\section{Determinantes e dificuldades de crescimento}

Variáveis em nível do indivíduo, da empresa e do ambiente podem influenciar o crescimento de empresas (Wiklund, Patzelt, \& Shepherd, 2009). Em nível do indivíduo, há evidências que o nível educacional e a experiência de empreendedores exercem efeito favorável sobre o crescimento. É relevante também a experiência de empreendedores no setor de atuação, o que confere a eles maior conhecimento do mercado, implicando em maiores chances de crescimento (Dobbs \& Hamilton, 2007; Lasch et al., 2007; Rauch \& Rijskjik, 2013). Ademais, a experiência de empreendedores na criação e na gestão de outros empreendimentos confere-lhes vantagens para promover o crescimento de seus negócios (Barringer, Jones \& Neubam, 2005; Davidsson et al., 2010). Adicionalmente, fatores psicológicos, como a motivação e aspirações de crescimento, assim como o lócus interno de controle, intenções ou expectativas de crescimento por parte de empreendedores apresentaram efeitos positivos sobre o crescimento de empresas (Davidsson et al., 2010; Levie \& Lichestein, 2010). Há evidências que a expectativa de crescimento tenha associação com o estágio do empreendimento, sendo que no estágio inicial, a tendência é que as expectativas de crescimento sejam maiores (Wright \& Stigliani, 2012). Outro aspecto que determina o crescimento de empresas, sobretudo de pequenas empresas, é o engajamento de empreendedores em redes de empresas ou em redes sociais (Barringer et al., 2005; Davidsson et al., 2010; Rauch \& Rijskijk, 2013). Redes constituem "formas de compartilhar informações, selecionar e acumular informações vindas do ambiente externo. Elas são disseminadoras e amplificadoras de informações para as empresas" (Julien, 2010, p. 215) e, nesse sentido, a inserção em redes pode contribuir para o empoderamento de pequenos empreendedores, habilitando-os a competirem com grandes empresas. Para gerar inovação em empresas de base tecnológica é interessante a dinâmica complementar entre grandes e pequenas empresas (Rannikko, 2012). Contudo, é preciso que a rede seja fonte de informações novas, variadas e de qualidade e que se conecte com o ambiente externo (Julien, 2010).

Em nível da empresa, estratégias de crescimento mostraram-se importantes para determinar o crescimento. Entre estas, destacam-se as estratégias de produção voltadas ao melhoramento, desenvolvimento e inovação de produtos (Achtenhagen et al., 2010; Davidsson et al., 2010; Dobbs \& Hamilton, 2007; Löfsten, 2016; Moreno \& Casillas, 2008), ressaltando a importância de patentes, que representam fatores estratégicos para empresas de base tecnológica (Löfsten, 2016). Destacam-se também estratégias de mercado, como o aproveitamento de nichos de mercado e a segmentação e diversificação de mercados. Além destas, estratégias voltadas à distribuição e ao posicionamento do produto no mercado, bem como o aumento de atividades de marketing contribuem para o crescimento (Brush et al., 2009; Davidsson et al., 2010; Lasch et al., 2007). Além disso, o estímulo ao conhecimento, ao aprendizado e a análise da tecnologia são importantes para o crescimento de empresas de base tecnológica (Löfsten, 2016). Nesse sentido, recorrer a especialistas e a consultores e utilizar capacidades decorrentes do processo de aprendizado contribuem para o crescimento (Davidsson et al., 2010; Reid \& Xu, 2012; Teruel-Carrizosa, 2010). Ademais, o crescimento para pequenas empresas pode ser obtido por meio da estratégia de parcerias com fornecedores e de estratégias de internacionalização (Achtenhagen et al., 2010; Coad \& Tamvada, 2012; Davidsson et al., 2010). Além disso, o crescimento está associado à adoção de uma política de recursos humanos, incluindo treinamentos e incentivos monetários (Antoncic \& Antoncic, 2011; Barringer et al., 2005; Dobbs \& Hamilton, 2007; Rauch \& Rijskijk, 2013). Além dessas estratégias, a cultura da empresa pode apresentar efeito positivo sobre o crescimento (Antoncic \& Antoncic, 2011), pois uma cultura que valorize o crescimento e o desenvolvimento de capacidades internas favorece o crescimento da empresa (Achtenhagen et al., 2010).

Com relação à influência de variáveis do ambiente sobre o crescimento de empresas, destacamse o efeito positivo da aglomeração industrial (Brito, Brito, Porto, \& Szilagyi, 2010; Hoogstra \& Kijk, 2004) e de condições de oferta e demanda do mercado sobre o crescimento (Coad \& Tamvada, 2012; Wright \& Stigliani, 2012). O dinamismo do setor e barreiras de entrada também podem influenciar positiva ou negativamente o crescimento (Davidsson et al., 2010). Ainda no ambiente, a presença de investidores e de capital de risco, bem como a presença de universidades e de mecanismos de 
transferência de tecnologia mostraram-se favoráveis ao crescimento, principalmente para empresas de base tecnológica (Davidsson et al., 2010; Hermans et al., 2012). É importante também a disponibilidade de recursos humanos e de matéria prima (Coad \& Tamvada, 2012; Lasch et al., 2007; Schoonjans, Van Cauwenberge, \& Bauwhede, 2013).

A Tabela 1 apresenta um resumo das determinantes de crescimento por nível micro (indivíduo), intermediário (empresa) e macro (ambiente) de análise.

Tabela 1

\section{Determinantes de Crescimento}

\begin{tabular}{|c|c|c|}
\hline Nível & Determinante & Autor \\
\hline \multirow[t]{2}{*}{ Indivíduo } & $\begin{array}{l}\text { Nível educacional e experiência de empreendedores } \\
\text { com crescimento, bem como experiência no setor } \\
\text { de atuação. }\end{array}$ & $\begin{array}{l}\text { Dobbs e Hamilton (2007); Rauch e } \\
\text { Rijskjik (2013). }\end{array}$ \\
\hline & $\begin{array}{l}\text { Experiência na criação e gestão de outros } \\
\text { empreendimentos. }\end{array}$ & $\begin{array}{l}\text { Barringer, Jones e Neubam (2005); } \\
\text { Davidsson et al. (2010). }\end{array}$ \\
\hline Indivíduo & $\begin{array}{l}\text { Motivação para o crescimento e aspirações de } \\
\text { crescimento e elevado lócus interno de controle. }\end{array}$ & Davidsson et al. (2010). \\
\hline \multirow[t]{2}{*}{ Indivíduo } & Intenção ou expectativa de crescimento. & Levie e Lichestein (2010). \\
\hline & $\begin{array}{l}\text { Engajamento de empreendedores em redes de } \\
\text { empresas ou em redes sociais }\end{array}$ & $\begin{array}{l}\text { Barringer et al. (2005); Davidsson et al. } \\
\text { (2010); Rauch e Rijskijk (2013). }\end{array}$ \\
\hline \multirow[t]{3}{*}{ Empresa } & $\begin{array}{l}\text { Estratégias de crescimento, estratégias de produção } \\
\text { voltadas ao melhoramento e inovação de produtos e } \\
\text { patentes. Estratégias de mercado, como o } \\
\text { aproveitamento de nichos de mercado e a } \\
\text { segmentação e diversificação de mercados. } \\
\text { Estratégias voltadas à distribuição e } \\
\text { posicionamento no mercado, bem como o aumento } \\
\text { de atividades de marketing. }\end{array}$ & $\begin{array}{l}\text { Achtenhagen et al. (2010); Brush, Ceru e } \\
\text { Blackburn (2009); Davidsson et al. } \\
\text { (2010); Dobbs e Hamilton (2007); } \\
\text { Lasch, Le Roy e Yami (2007); Löfsten } \\
\text { (2016); Moreno e Casillas (2008). }\end{array}$ \\
\hline & $\begin{array}{l}\text { Recorrer a especialistas e a consultores, assim como } \\
\text { utilizar capacidades decorrentes do processo de } \\
\text { aprendizado. }\end{array}$ & $\begin{array}{l}\text { Davidsson et al. (2010); Reid e Xu } \\
\text { (2012); Teruel-Carrizosa (2010). }\end{array}$ \\
\hline & $\begin{array}{l}\text { Parcerias com fornecedores e estratégias de } \\
\text { internacionalização. }\end{array}$ & $\begin{array}{l}\text { Achtenhagen et al. (2010); Coad e } \\
\text { Tamvada (2012); Davidsson et al. (2010). }\end{array}$ \\
\hline \multirow[t]{2}{*}{ Empresa } & $\begin{array}{l}\text { Política de Recursos Humanos com incentivos } \\
\text { financeiros e treinamentos voltados ao } \\
\text { desenvolvimento de pessoal, de modo a propiciar a } \\
\text { satisfação dos empregados. }\end{array}$ & $\begin{array}{l}\text { Antoncic e Antoncic (2011); Barringer } \\
\text { et al. (2005); Dobbs e Hamilton (2007); } \\
\text { Rauch e Rijskijk (2013). }\end{array}$ \\
\hline & $\begin{array}{l}\text { Cultura da empresa, que valorize o crescimento e o } \\
\text { desenvolvimento de capacidades internas. }\end{array}$ & $\begin{array}{l}\text { Achtenhagen et al. (2010); Antoncic e } \\
\text { Antoncic, (2011). }\end{array}$ \\
\hline \multirow[t]{5}{*}{ Ambiente } & Aglomeração industrial. & Hoogstra e Kijk (2004). \\
\hline & Condições de oferta e demanda do mercado. & $\begin{array}{l}\text { Coad e Tamvada (2012); Wright e } \\
\text { Stigliani, (2012). }\end{array}$ \\
\hline & Barreiras de entrada e dinamismo do setor. & Davidsson et al. (2010). \\
\hline & $\begin{array}{l}\text { Presença de investidores, de capital de risco e de } \\
\text { universidades no ambiente. }\end{array}$ & $\begin{array}{l}\text { Davidsson et al. (2010); Hermans et al. } \\
\text { (2012); Lasch et al. (2007). }\end{array}$ \\
\hline & $\begin{array}{l}\text { Disponibilidade de recursos humanos e de matéria } \\
\text { prima. }\end{array}$ & $\begin{array}{l}\text { Coad e Tamvada (2012); Schoonjans, } \\
\text { Van Cauwenberge e Bauwhede (2013). }\end{array}$ \\
\hline
\end{tabular}

RAC, Rio de Janeiro, v. 22, n. 6, art. 1, pp. 817-840, novembro/dezembro, 2018, http://rac.anpad.org.br $($ (c) )EY 
Quanto às dificuldades de crescimento de pequenos negócios, estas também podem ser associadas às variáveis do ambiente, do negócio ou do empreendedor. No que se refere ao empreendedor, a falta de qualificação pessoal, de experiência gerencial (Penrose, 2006) e de conhecimento do setor (Brush, 1992) podem representar dificuldades para o crescimento de empresas. Entre as variáveis em nível da empresa que podem dificultar o crescimento do negócio, ressaltam-se: a falta de estratégias de crescimento e de uma política de qualificação de pessoal (Davidsson et al., 2010). Outra dificuldade consiste na falta de informações e de recursos tecnológicos por parte da empresa (Penrose, 2006).

Quanto às variáveis do ambiente que podem dificultar o crescimento da empresa, foram identificadas: a falta de pessoas qualificadas e a ausência de universidades (Davidsson et al., 2010; Hermans et al., 2012). Além destas, a escassez de recursos no ambiente, a indisponibilidade de capital, bem como taxas e impostos elevados podem limitar o crescimento (Davidsson et al., 2010). Lasch et al. (2007) assinalam que o financiamento e os clientes são fatores críticos para o crescimento de empresas de base tecnológica, sendo que eles identificaram correlação positiva entre crescimento das empresas e número de clientes.

Em síntese, essas foram as dificuldades e as determinantes de crescimento identificadas na literatura. É necessário identificar elementos associados a empresas de base tecnológica, que são alicerçadas em conhecimento, enfrentam um ambiente competitivo e um mercado dinâmico. Além disso, poucos estudos exploraram aspectos subjetivos de empreendedores associados a dificuldades e determinantes de crescimento.

\section{Procedimentos Metodológicos}

A pesquisa realizada é qualitativa, um estudo descritivo. A pesquisa qualitativa explora os fenômenos em profundidade, analisa múltiplas realidades subjetivas e é um processo indutivo, contextualizando o fenômeno com riqueza interpretativa (Sampieri, Collado, Lucio, \& Baptista, 2013). Tem-se como questão de pesquisa: O que determina e o que dificulta o crescimento de empresas de base tecnológica na visão de empreendedores do setor de software?, a pesquisa tem seu posicionamento epistemológico no paradigma interpretativista, buscando significados e interpretações que atores atribuem a determinado fenômeno, a fim de descrevê-lo de modo holístico, próximo às realidades dos sujeitos (Leitch et al., 2010).

Os sujeitos da pesquisa foram pequenos empreendedores do setor de software, cujas empresas estão localizadas em duas cidades de porte médio nos estados de Santa Catarina e do Paraná. Eles foram indicados pela coordenação de um arranjo local de empresas, constituído por 80 empresas, no caso do Paraná. Em Santa Catarina, a indicação ocorreu por uma associação de empresários. Participaram da pesquisa seis empreendedores, seguindo parâmetros de Eisenhardt (1989). Os critérios de escolha das empresas foram: o número de empregados, sendo no máximo 200 funcionários, e o tempo de atividades, ao menos 5 anos, tempo considerado necessário para propiciar uma avaliação do fenômeno em questão, o crescimento.

O método de coleta de dados foi a entrevista semiestruturada, orientada para compreender como os empreendedores contextualizavam o fenômeno do crescimento, quais agentes determinavam e quais o dificultavam (Downing, 2005), partindo do pressuposto que os discursos são imbuídos de significados (Denzin \& Lincoln, 2001). Três questões nortearam as entrevistas: O que contribuiu para o crescimento do seu negócio? O que dificultou o crescimento do seu negócio? Quem contribuiu para o crescimento? Ao final das entrevistas, foi sugerido aos participantes que falassem espontaneamente sobre o crescimento de seu empreendimento.

Foram realizadas seis entrevistas com os empreendedores que estavam à frente dos empreendimentos. Como procedimento ético, para cada entrevistado foi entregue um termo de consentimento, explicitando os objetivos da pesquisa, solicitando autorização para gravação e 
assegurando a confidencialidade dos dados. A duração das entrevistas variou entre cinquenta minutos e uma hora e cinquenta minutos, como mostrado na Tabela 2.

Tabela 2

\section{Duração das Entrevistas}

\begin{tabular}{ccc}
\hline Empreendedor & Duração da Entrevista & Páginas de transcrição \\
\hline A & 50 minutos & 11 \\
\hline B & 1hora e 12 minutos & 13 \\
\hline C & 58 minutos & 11 \\
\hline D & 1hora e 14 minutos & 13 \\
\hline E & 1hora e 02 minutos & 12 \\
\hline F & 1 hora e 50 minutos & 21 \\
\hline
\end{tabular}

A transcrição foi realizada logo após cada entrevista e, em seguida, o material transcrito foi enviado, por e-mail, a cada participante, como critério de validade e confiabilidade (Kirk \& Miller, 1986). Todos os participantes validaram o conteúdo das transcrições e, após isso, o material foi utilizado para análise dos dados.

Para análise dos dados, inicialmente, conduziu-se uma análise prévia, por meio de leitura das transcrições, analisando a exaustividade e a homogeneidade do material, como sugere Bardin (2011). Em seguida, procedeu-se à análise clássica de conteúdo e o material foi codificado (Bauer \& Gaskell, 2007). A codificação ocorreu a partir da busca de códigos analíticos e os critérios de codificação foram o axial, em que: "as categorias são refinadas, desenvolvidas e relacionadas ou interconectadas" (Gibbs, 2009, p. 72); e o semântico (Bardin, 2011), tendo como procedimento o "acervo", ou seja, o título definido no final da operação (Bardin, 2011, p. 147). Para codificação e categorização do material, utilizou-se o software NVivo versão 9. Este software auxilia o pesquisador na análise de dados qualitativos, tendo sido utilizada a análise clássica de conteúdo (Leech \& Onwegbuzie, 2011). Embora a utilização do software propicie outras formas de análise como, por exemplo, análises comparativas, para esta pesquisa optou-se pela análise de conteúdo porque o objetivo não era comparar as determinantes e as dificuldades entre os empreendedores. O que se buscou foi ampla compreensão do crescimento, a partir de diferentes perspectivas de empreendedores de base tecnológica. Então, o material foi codificado em duas grandes categorias (de forma dedutiva): determinantes e dificuldades de crescimento. Para cada uma dessas categorias foram identificados subtemas ou códigos hierárquicos, de forma indutiva (Houghton et al., 2016). Para assegurar a validade da pesquisa, como recomendam Bauer e Gaskell (2007), a codificação levou em consideração as palavras do texto (validade semântica) e representou o conteúdo dos participantes (validade da amostra) e a teoria subjacente (validade de construto).

As categorias finais para determinantes do crescimento foram: inovação, recursos humanos, apoio de outras instituições e outras determinantes. Para as dificuldades de crescimento, as categorias foram: demora no desenvolvimento do produto, dificuldade relacionada à formação e contratação de pessoas, concorrência com grandes empresas e cultura.

\section{Análise dos Resultados}

Para fins de contextualização, as Tabelas 3 e 4 apresentam um perfil dos participantes da pesquisa e das empresas, respectivamente. 
Tabela 3

Perfil dos Participantes

\begin{tabular}{|c|c|c|c|c|c|}
\hline Caso & Número de Sócios & Escolaridade & $\begin{array}{l}\text { Idade quando } \\
\text { abriu a empresa }\end{array}$ & $\begin{array}{l}\text { Idade } \\
\text { atual }\end{array}$ & Ocupação anterior \\
\hline A & $\begin{array}{l}2 \text { no início e } 1 \\
\text { atualmente }\end{array}$ & $\begin{array}{c}\text { Graduação em Ciência da } \\
\text { Computação }\end{array}$ & 28 & 38 & $\begin{array}{c}\text { Trabalhava em uma } \\
\text { grande empresa. }\end{array}$ \\
\hline B & 1 sócio & $\begin{array}{l}\text { Graduação em Engenharia } \\
\text { Civil e em Administração }\end{array}$ & 30 & 47 & $\begin{array}{l}\text { Trabalhava em } \\
\text { empresa da família. }\end{array}$ \\
\hline $\mathrm{C}$ & 3 sócios & $\begin{array}{l}\text { Graduação em Ciência da } \\
\text { Computação e em } \\
\text { Administração }\end{array}$ & 30 & 40 & $\begin{array}{c}\text { Trabalhava em uma } \\
\text { grande empresa de } \\
\text { software. }\end{array}$ \\
\hline $\mathrm{D}$ & 1 sócio & $\begin{array}{l}\text { Graduação em Ciência da } \\
\text { Computação e Pós- } \\
\text { Graduação em } \\
\text { Administração }\end{array}$ & 30 & 47 & $\begin{array}{l}\text { Trabalhava em uma } \\
\text { grande empresa. }\end{array}$ \\
\hline $\mathrm{E}$ & 1 sócio (esposa) & $\begin{array}{l}\text { Graduação em História e } \\
\text { MBA em Gestão }\end{array}$ & 30 & 37 & $\begin{array}{l}\text { Trabalhava em uma } \\
\text { grande empresa do } \\
\text { setor de software. }\end{array}$ \\
\hline $\mathrm{F}$ & 1 sócio & $\begin{array}{c}\text { Graduação em Ciência da } \\
\text { Computação }\end{array}$ & 27 & 55 & $\begin{array}{c}\text { Trabalhava no setor } \\
\text { de TI de uma grande } \\
\text { empresa. }\end{array}$ \\
\hline
\end{tabular}

Todos os participantes eram jovens quando começaram a empresa e a média de idade deles no momento da abertura da empresa é 29 anos. Todos trabalharam em uma grande empresa antes de iniciar o empreendimento, apenas B trabalhava para empresa da família. Desta forma, a maioria das empresas formou-se como empresas independentes, porém os empreendedores trabalharam anteriormente em grandes empresas e podem pode ser considerados como spin-offs corporativos. Segundo Rannikko (2012), empreendedores de base tecnológica podem ser classificados em: spin-offs de universidades, spin-offs corporativos ou empresas independentes. A maioria dos empreendedores tem formação escolar na área de Ciência da Computação. Apenas dois deles não tinham essa formação, um é Engenheiro Civil, mas tem como sócio um graduado na área de Ciência da Computação e outro, o caso E, formado em História, mas trabalhou anteriormente, durante 12 anos, em uma grande empresa de software.

Os empreendedores tinham algum conhecimento do ramo antes de criar o próprio empreendimento, o que é relevante para eliminar possível viés derivado de falta de conhecimento no ramo. A Tabela 4 apresenta o perfil das empresas.

Tabela 4

\section{Perfil das Empresas}

\begin{tabular}{clcc}
\hline Caso & Foco de atuação & Ano de criação & $\begin{array}{c}\text { Número de } \\
\text { funcionários }\end{array}$ \\
\hline A & NF eletrônica & 2006 & 50 \\
\hline B & RP para indústrias pequenas & 2000 & 39 \\
\hline C & CRM para pequenas empresas & 2006 & 09 \\
\hline D & Software para grandes empresas na área de saúde & 2000 & 200 \\
\hline E & Softwares para empresas em geral & 2010 & 35 \\
\hline F & Softwares para hotéis, restaurantes, postos de gasolina. & 1988 & 110 \\
\hline
\end{tabular}

RAC, Rio de Janeiro, v. 22, n. 6, art. 1, pp. 817-840, novembro/dezembro, 2018, http://rac.anpad.org.br (oc) E्EY 
As empresas atuam no setor de software, mas apresentam heterogeneidade quanto ao foco de atuação. Quanto à idade delas, apenas uma foi criada antes do ano 2000. A empresa mais nova foi aberta em 2010 e tinha seis anos de atividade quando a pesquisa foi realizada. As empresas D e F são as que possuem o maior número de funcionários e a empresa $\mathrm{C}$ possui o menor número. Desta forma, o conjunto de participantes reflete um critério homogêneo em termos de setor de atividade e foco de atuação no desenvolvimento de software, mas apresenta também heterogeneidade quanto ao tempo de experiência e ao número de funcionários. Essa heterogeneidade mostrou-se favorável para o propósito da pesquisa, que não era o de estabelecer comparações entre os empreendedores.

\section{Determinantes do crescimento}

Empresas do setor de software têm no conhecimento um dos seus principais ativos (Apostolou \& Mentzas, 2003). Ao expressarem sobre o que determina o crescimento das empresas pequenas de base tecnológica, os empreendedores desta pesquisa não mencionaram o conhecimento, mas a inovação, como se observa na Tabela 5. A inovação é um processo dinâmico, derivado do conhecimento acumulado por meio de aprendizado e da interação, consistindo na "implementação de um produto (bem ou serviço) novo ou significativamente melhorado, ou um processo, ou um novo método de marketing, ou um novo método organizacional nas práticas de negócios, na organização do local de trabalho ou nas relações externas" (Organisation for Economic Co-operation and Development e Financiadora de Estudos e Projetos [OECD/FINEP], 1997, p. 55).

Tabela 5

\section{Determinantes do Crescimento - Inovação}

\begin{tabular}{cl}
\hline Caso & Trecho da Entrevista \\
\hline A & "Estamos fazendo um portfólio com inovação, sempre tendo novidades, mesmo sendo software, ele \\
& tem tempo de vida, não fica a vida inteira tendo a mesma versão. Você tem que colocar novos produtos \\
então ter um portfólio sempre oxigenado e, para isso, o processo de inovação tem que estar rolando, \\
faz parte do modelo."
\end{tabular}

O empreendedor A considera que a inovação não é apenas determinante do crescimento, mas da sobrevivência do empreendimento, cujo produto tem um ciclo de vida curto. Para o empreendedor $\mathrm{C}$, a inovação é um diferencial, importante para possibilitar a conquista de uma fatia de mercado, que é dominado por grandes empresas. Em razão dessa concorrência, a maior parte de empresas pequenas de base tecnológica atua em nichos de mercado (Santos \& Pinho, 2010). Da mesma forma, para o empreendedor F, a inovação no produto é uma estratégia para concorrer com as grandes empresas. Ele ressalta que essa estratégia caminha junto com a empresa desde o início e que os clientes são parceiros com novas ideias. Essa visão é corroborada por Apostolou e Mentzas (2003), para os quais a captura de

RAC, Rio de Janeiro, v. 22, n. 6, art. 1, pp. 817-840, novembro/dezembro, 2018, http://rac.anpad.org.br (cc) EY 
ideias de clientes é relevante para geração de conhecimento em empresas de software, representando uma fonte de conhecimento para construção de habilidades e para inovação no produto. Para o empreendedor $\mathrm{D}$, a inovação não se restringe ao produto, mas também ao processo de venda, cuja finalidade principal é a de reter clientes, na medida em que, ao mesmo tempo em que atuam com conhecimento e inovação, com o desenvolvimento de produtos, essas empresas também prestam serviços e dependem dos clientes para sobreviverem. Para Lasch et al. (2007), clientes constituem um dos fatores críticos para o crescimento de pequenas empresas de base tecnológica. Apenas o empreendedor E não mencionou a inovação, no entanto, está desenvolvendo um projeto inovador, com apoio de um órgão financiador do Governo Federal.

A importância da inovação para o crescimento de pequenas empresas foi mencionada por Achtenhagen et al. (2010), Davidsson et al. (2010) e Moreno e Casilas (2008). Nesta pesquisa, os empreendedores consideram a inovação uma condição do modelo de gestão para as empresas crescerem, pois elas precisam competir com as grandes e, além disso, precisam reter os clientes, por meio da oferta de produtos e serviços inovadores. De acordo com os depoimentos, mostrados na Tabela 5, a inovação é importante para sobrevivência, competitividade, manutenção de clientes e busca por novos clientes. Lasch et al. (2007) salientam que a retenção de clientes é um fator crítico para empresas de base tecnológica, sendo que, nesta pesquisa, os resultados mostraram que as empresas utilizam a inovação como um recurso para reter e conquistar novos clientes, e como uma estratégia para competir com grandes empresas do setor, na forma de uma orientação empreendedora (Lumpkin \& Dess, 1996; Rannikko, 2012), que consiste em uma orientação estratégica, composta por cinco dimensões: "propensão ao risco, proatividade, inovação, ousadia e agressividade competitiva" (Rannikko, 2012, p. 8). Outra determinante para o crescimento foi a política de recursos humanos. Para os participantes desta pesquisa, a equipe é o maior patrimônio da empresa e é o que define o seu valor de mercado. Na Tabela 6 são apresentadas as subcategorias de recursos humanos, que são: seleção, valorização da equipe, além de capacitação, qualificação e treinamento.

Tabela 6

\section{Determinantes de Crescimento - Recursos Humanos}

\begin{tabular}{ll}
\hline Subcategorias & Visão do Empreendedor \\
\hline Relevância da seleção de pessoas & "Para atingir o crescimento, é preciso achar a pessoa certa no lugar certo, \\
& ou seja, tem que achar quem vai fazer o melhor para você naquela \\
& operação, por exemplo, tem uma pessoa que precisa fazer gestão de \\
& Recursos Humanos, eu preciso de alguém que faça isso muito bem feito, \\
& se eu trouxer alguém da área técnica, que não faz bem feito, eu vou levar \\
& um tempo para preparar. Eu preciso, por exemplo, de um gerente de \\
projeto e precisa cuidar muito bem, tem um perfil muito específico e é & muito importante" (D).
\end{tabular}

Valorização da equipe por meio de "Todo funcionário com mais de cinco anos está na nossa parede da fama. incentivos: $\quad$ Se você observar, tem bastante.... temos ali dois supervisores que completaram cinco anos na empresa, são dois supervisores, são líderes de equipe e eles foram contratados dentro de um programa de qualificação para inclusão social, inclusão digital, que fizemos parceria com universidades....... Como o nosso grupo de colaboradores é muito jovem, o jovem é muito ansioso, ele não quer esperar um ano para saber se talvez ele vai ter uma bonificação. Então nós implantamos uma metodologia que a bonificação é mensal, ele fez, já recebe" (A). 


\section{Tabela 6 (continuação)}

\begin{tabular}{|c|c|}
\hline Subcategorias & Visão do Empreendedor \\
\hline \multirow{2}{*}{$\begin{array}{l}\text { Valorização da capacitação e da } \\
\text { qualificação da equipe }\end{array}$} & $\begin{array}{l}\text { "a capacitação para essas pessoas internamente porque eles não vêm } \\
\text { pronto e quando eles entram aqui, eu preciso formar eles dentro daquilo } \\
\text { que eu preciso porque tem algumas coisas bem particulares. Então, eu } \\
\text { preciso trabalhar a formação" (D). }\end{array}$ \\
\hline & $\begin{array}{l}\text { "A gente tem alguns incentivos aqui dentro, a gente tem um RH e faz } \\
\text { várias palestras promocionais, a gente faz eventos, por exemplo, dia } \\
\text { primeiro de maio agora a gente vai reunir, vai trazer todos os escritórios } \\
\text { na cidade X, a gente vai reunir, vai vir mais de } 250 \text { pessoas aqui, final de } \\
\text { ano a gente faz confraternização em todas as unidades" (F). }\end{array}$ \\
\hline Treinamento de pessoas & $\begin{array}{l}\text { "No meu caso é treinamento de pessoas, na verdade processos e pessoas } \\
\text { não têm jeito, se você tiver um processo amarrado vai acontecer, mas se } \\
\text { você tiver um bando de pessoas muito boas, competentes e não tiver um } \\
\text { processo desenhado você não vai atingir, então, o meu objetivo é cada vez } \\
\text { mais treinar" (D). }\end{array}$ \\
\hline
\end{tabular}

$\mathrm{O}$ rigor na seleção de pessoas foi uma determinante mencionada pelo empreendedor $\mathrm{D}$, que ressaltou não apenas a seleção para a área técnica, mas também para a área gerencial. Quanto à valorização da equipe por meio de incentivos, o empreendedor A implementou a parede da fama, uma parede na entrada da empresa que contém fotos de todos os empregados com cinco anos ou mais de atividade na empresa, como uma estratégia de valorização e retenção de pessoas. A retenção de recursos humanos nessas empresas é um fator crítico para o crescimento de empresas de software (Apostolou \& Mentzas, 2003). Outra estratégia da empresa A consiste na participação em programas, em conjunto com universidades locais, para formação de pessoas recrutadas em comunidades de baixa renda. Dois dos figurantes na parede da fama foram recrutados em um desses programas que a empresa participou. Aliada à política de valorização da permanência na empresa, essa empresa implementou uma bonificação mensal por produtividade para a maioria dos trabalhadores da área, que são jovens.

Os empreendedores D e F enfatizaram a relevância da capacitação e qualificação das pessoas. Para F, a capacitação é fornecida em eventos, palestras e confraternização. O empreendedor D enfatizou a relevância do treinamento, aliada à definição de processos. Esses resultados corroboram com outros apontados na literatura, que apresentaram como determinantes de crescimento a concessão de incentivos financeiros e treinamentos a funcionários (Barringer et al., 2005; Rauch \& Rijskik, 2013). Ressalta-se que o empreendedor $\mathrm{D}$ foi o que apontou maior número de estratégias de recursos humanos para o crescimento da empresa (seleção, qualificação e treinamento), o que pode estar associado ao fato da empresa ter o maior número de funcionários e de ter como clientes grandes empresas.

A terceira categoria de determinantes de crescimento é o apoio de outras instituições, mostrada na Tabela 7.

RAC, Rio de Janeiro, v. 22, n. 6, art. 1, pp. 817-840, novembro/dezembro, 2018, http://rac.anpad.org.br (cc) E 
Tabela 7

\section{Instituições que Contribuíram para o Crescimento}

\begin{tabular}{ll}
\hline Órgão/Instituição & Tipo de apoio \\
\hline $\begin{array}{l}\text { Associação de Empresas de Software do } \\
\text { Município }\end{array}$ & Cooperação entre as empresas, informaçães diversas. \\
\hline $\begin{array}{l}\text { Associação de Empresas de Software do } \\
\text { Município }\end{array}$ & Informações de outras empresas do Estado. \\
\hline SEBRAE & Atuação junto à Associação de Software, com consultoria \\
\hline FINEP & Financiamento de projeto inovador \\
\hline BNDES & Concessão de linha de crédito \\
\hline Universidades & Parcerias em projetos e fornecimento de mão de obra qualificada \\
\hline SENAI & Bolsas de estudos a estagiários \\
\hline Centro de Inovação Tecnológica & Bolsas de estudos a estagiários \\
\hline Grandes empresas & Parceria com projeto inovador e indicação de novos clientes \\
\hline
\end{tabular}

Entre as empresas localizadas no Estado do Paraná, duas delas reconhecem a importância da Associação de Empresas de Software para o crescimento da Empresa. Outras duas mencionaram a participação do Serviço Brasileiro de Apoio à Micro e Pequena Empresa (SEBRAE). Uma das empresas citou que a participação da Financiadora Brasileira de Estudos e Projetos (FINEP) foi importante, por meio de financiamento de projeto, como também o Banco Nacional de Desenvolvimento Econômico (BNDES), com a concessão de linha de crédito. O incentivo financeiro aparece na literatura como uma determinante do crescimento (Barringer et al., 2005; Rauch \& Rijskik, 2013), contudo, nesta pesquisa apenas uma empresa fez referência este aspecto, o que pode estar associado ao fato da maioria das empresas desta pesquisa ter adotado como estratégia uma política financeira conservadora, sem recorrer a capital de terceiros.

Para quatro das empresas que participaram desta pesquisa, o apoio de universidades locais foi relevante para formação de mão de obra e para parcerias em projetos. Uma das empresas citou o apoio do Centro de Inovação Tecnológica e do Serviço Nacional da Indústria, por meio da concessão de bolsas de estudos a estudantes que atuaram nas empresas. Estudos anteriores ressaltaram a atuação em conjunto com universidades, como forma de desenvolver conhecimento e atingir crescimento, principalmente para empresas de base tecnológica (Davidsson et al., 2010; Hermans et al., 2012; Moretti \& Crnkovic, 2015; Tumelero et al., 2015). Os resultados da cooperação entre as empresas desta pesquisa com universidades limitaram-se à concessão de bolsas de estudos, não ampliando para outras formas como patentes ou desenvolvimento de pesquisas, que poderiam representar maior contribuição para o crescimento das empresas (Löfsten, 2016; Stam \& Wennberg, 2009).

Uma das empresas desta pesquisa citou o apoio da Associação Comercial do Município e da Associação de Software do Estado. Nesse caso, as redes de empresas em nível de município e de Estado, mostraram-se favoráveis ao crescimento, corroborando resultados de estudos anteriores com empresas em outros setores que não o de software (Barringer et al., 2005; Davidsson et al., 2010; Rauch \& Rijskijk, 2013). Nesta pesquisa, todas as empresas que atuam no Estado que conta com associações de empresas de software afirmaram que esta rede foi relevante para o crescimento delas. Do mesmo modo, outra pesquisa, também realizada junto a empresas participantes do Arranjo Produtivo de Empresas de software do Estado do Paraná, constatou que a cooperação favoreceu o desenvolvimento de produtos e processos e a capacitação de recursos humanos das empresas, propiciando a melhoria da qualidade dos produtos, processos produtivos e recursos humanos, favorecendo ainda novas oportunidades de negócios (Gussoni, Weise, \& Medeiros, 2015). 
Três das empresas pesquisadas mencionaram a relevância de grandes empresas para o crescimento delas. Uma delas enfatizou o aprendizado obtido a partir do conhecimento da cadeia de operações e de distribuição em grande volume de serviços, o que contribuiu para a construção de soluções semelhantes, mesmo atuando em outro segmento. Outra empresa destacou a relevância de duas grandes empresas, com as quais firmou parcerias, sendo uma delas para lançamento de um produto inovador e outra para entrar em conjunto no mercado peruano. Além disso, esta mesma empresa citou o apoio de outras duas grandes empresas que atuam na construção de hotéis (uma com fechaduras e outra com parte elétrica) e que indicam o produto dela para outros potenciais clientes. Esses resultados mostraram a importância da dinâmica complementar dessas pequenas empresas com grandes empresas para gerar conhecimento e inovação, como também constatou Rannikko (2012).

Os empreendedores, com isso, reconhecem que o crescimento é um fenômeno coletivo favorecido pelo apoio de outras instituições, tais como universidades, SEBRAE, FINEP, BNDES, SENAI, como também grandes empresas, corroborando com Leitch, Hill e Harrison (2010), que afirmaram que o empreendedor conta com apoio de outros para crescer. Essas instituições com as quais as empresas mencionaram o apoio recebido caracterizam-se como redes informacionais para as empresas, sendo fontes de compartilhamento de conhecimento e informação (Julien, 2010).

Além da inovação, de recursos humanos e de apoio de outras pessoas e instituições, os empreendedores mencionaram outras determinantes, como a conquista de certificações, participação em Feiras, ritmo intenso de trabalho, uma política de reinvestimento e apoio de consultores, como mostrado na Tabela 8 .

Tabela 8

\section{Outras Determinantes de Crescimento}

\begin{tabular}{|c|c|c|}
\hline Nível & Determinante & Visão dos Empreendedores \\
\hline Empresa & $\begin{array}{l}\text { Conquista de } \\
\text { certificações }\end{array}$ & $\begin{array}{l}\text { "Aí então eu acho que estar na mídia das melhores empresas para se trabalhar } \\
\text { de tecnologia foi realmente a cereja do bolo, mas para chegar aí, todo esse } \\
\text { trabalho, desde lá da base, da mão de obra, dos processos, da certificação de } \\
\text { qualidade, é um caminho muito longo" (A). }\end{array}$ \\
\hline Empreendedor & $\begin{array}{l}\text { Participação } \\
\text { em Feiras }\end{array}$ & $\begin{array}{l}\text { "Aí foi numa Feira muito grande que a gente participa lá em São Paulo e veio } \\
\text { um grupo econômico muito forte, que é o grupo XXX ..eles chegaram no } \\
\text { nosso estande e falaram: queria falar com o proprietário e eu estava ali, } \\
\text { participo de todas as Feiras, ....e outro parceiro grande foi sempre as Feiras, } \\
\text { é uma vitrine legal, a gente participa em torno de } 10 \text { Feiras por ano. Lá a } \\
\text { gente mostra o produto, tem contato com cliente, eu procuro participar de } \\
\text { todas elas para ficar mais próximo..." (F). }\end{array}$ \\
\hline \multirow[t]{2}{*}{ Empreendedor } & Dedicação & "Crescimento acontece com muito trabalho" (B). \\
\hline & $\begin{array}{l}\text { Intensa } \\
\text { trabalho }\end{array}$ & $\begin{array}{l}\text { "Eu vejo que aqui dentro o crescimento se dá pelo trabalho, quanto mais nós } \\
\text { fizermos pela organização de melhorias, de práticas, vamos crescer" }(\mathrm{F}) \text {. }\end{array}$ \\
\hline \multirow[t]{3}{*}{ Empresa } & Consultoria & $\begin{array}{l}\text { "Meia hora de consultoria vale mais do que dois anos de chicotada nas costas, } \\
\text { isto tem feito grande diferença" (C). }\end{array}$ \\
\hline & & $\begin{array}{l}\text { "Nós ficamos durante anos com um consultor da Fundação..... nós sempre } \\
\text { buscamos dicas de fora, sempre" }(\mathrm{E}) \text {. }\end{array}$ \\
\hline & & $\begin{array}{l}\text { "Nós tivemos muito apoio de consultores, eu contratei uma pessoa muito boa, } \\
\text { uma consultora, ela tem certificação MMI, ela trabalhou em uma grande } \\
\text { software house, morou na França muitos anos, trabalhou na área de TI ...ela } \\
\text { está aqui, ela acompanhou, faz } 5 \text { anos que ela presta uma consultoria, mas na } \\
\text { área de estrutura de fábrica" (F). }\end{array}$ \\
\hline Empresa & Reinvestir & $\begin{array}{l}\text { "Se você buscar só o resultado, ou seja, deu lucro e eu não reinvisto e só } \\
\text { tenho o benefício, o resultado trago para mim a longevidade, a } \\
\text { sustentabilidade da empresa vai ficar comprometida. ...você tem que crescer, } \\
\text { você tem que reinvestir uma parte daquilo que você conseguiu do lucro senão } \\
\text { você vai estar fora" (D). }\end{array}$ \\
\hline
\end{tabular}

RAC, Rio de Janeiro, v. 22, n. 6, art. 1, pp. 817-840, novembro/dezembro, 2018, http://rac.anpad.org.br (oc) EY 
De acordo com os resultados apresentados na Tabela 8, o crescimento pode ser atribuído a ações do empreendedor, como a dedicação intensa ao trabalho e a participação em Feiras, ou decorrente da gestão da empresa, tais como uma política de reinvestir, uma estratégia de busca de certificações e busca por consultorias, esta última mencionada por três empreendedores. O apoio de consultores é uma estratégia que empresas de software recorrem para acessar conhecimento de fontes externas (Apostolou \& Mentzas, 2003), sendo que, nesta pesquisa, as empresas recorreram a consultores para obter conhecimento administrativo, técnico e de mercado.

Os dados da pesquisa mostraram que os empreendedores apresentam uma compreensão de determinantes do crescimento que abrange ações do empreendedor, da empresa e do ambiente, corroborando com Wiklund et al. (2009). A Tabela 9 apresenta o agrupamento destas determinantes classificadas por indivíduo, empresa e ambiente.

Tabela 9

Determinantes de Crescimento para Pequenas Empresas de Software

\begin{tabular}{|c|c|c|}
\hline Nível & Categoria Determinante & SubCategorias \\
\hline Empreendedor & Ações do Empreendedor & $\begin{array}{l}\text { Participação em Feiras. } \\
\text { Dedicação intensa ao trabalho. } \\
\text { Engajamento em redes. }\end{array}$ \\
\hline Empresa & Inovação & $\begin{array}{l}\text { No produto. } \\
\text { No processo de vendas. }\end{array}$ \\
\hline Empresa & Política de Recursos Humanos & $\begin{array}{l}\text { Política de Seleção. } \\
\text { Valorização de Tempo de Trabalho. } \\
\text { Incentivos e ações para capacitação } \\
\text { e qualificação. } \\
\text { Pagamento de incentivos } \\
\text { financeiros. } \\
\text { Treinamento. }\end{array}$ \\
\hline Empresa & $\begin{array}{l}\text { Política Financeira } \\
\text { Outras }\end{array}$ & $\begin{array}{l}\text { Reinvestir recursos. } \\
\text { Busca por Certificações. } \\
\text { Consultorias. }\end{array}$ \\
\hline Ambiente & Apoio de Outras Instituições & $\begin{array}{l}\text { Universidades. } \\
\text { Grandes Empresas. } \\
\text { SEBRAE. } \\
\text { Arranjo Produtivo Local. } \\
\text { Redes de Empresas do Setor. } \\
\text { Consultores. }\end{array}$ \\
\hline
\end{tabular}

Estudos anteriores concluíram que o nível educacional do empreendedor e a experiência no setor de atuação influenciam o crescimento das empresas (Dobbs \& Hamilton, 2007; Rauch \& Rijskjik, 2013). Nesta pesquisa, todos os participantes tinham formação na área de Ciência da Computação e apresentavam experiência anterior no setor. No entanto, esses aspectos não foram mencionados por eles como determinantes do crescimento. Lasch et al. (2007) não identificaram relação entre a experiência dos empreendedores e o crescimento das empresas, sendo que eles consideraram que o fato de todos os empreendedores terem conhecimento e experiência no setor pode ter influenciado o resultado. Por sua vez, Rauch e Rijskijk (2013) identificaram que o conhecimento e experiência de empreendedores influenciou positivamente o crescimento apenas nos primeiros cinco anos. Portanto, são inconclusivos os resultados sobre os efeitos do capital humano de empreendedores de base tecnológica sobre o crescimento das empresas. Outro aspecto importante para o crescimento são intenções e expectativas, 
sendo que, nesta pesquisa, todos os participantes expressaram expectativas e intenções de crescimento, que são determinantes de crescimento (Davidsson et al., 2010).

Em nível da empresa, estudos anteriores mostraram a importância de estratégias em relação ao mercado e aos clientes, como, por exemplo, estratégias para distribuição, posicionamento e segmentação de mercado (Brush et al., 2009; Davidsson et al., 2010). Nesta pesquisa, os empreendedores enfatizaram a gestão interna, em termos de recursos humanos e de reinvestimento. Quanto aos recursos humanos, treinamentos e satisfação dos empregados podem contribuir para o crescimento (Antoncic \& Antoncic, 2011; Barringer et al., 2005; Dobbs \& Hamilton, 2007; Rauch \& Rijskijk, 2013). Nesta pesquisa, além desses aspectos, foram ainda salientados a seleção de pessoas e a valorização do tempo de trabalho.

Ainda como determinante de crescimento em nível de empresa, as empresas desta pesquisa mencionaram o apoio de consultores externos, citado em estudos anteriores (Davidsson et al., 2010; Reid \& Xu, 2012; Teruel-Carrizosa, 2010). Além disso, enfatizaram a importância de buscar certificações, não comentada em estudos anteriores.

Quanto às variáveis do ambiente que favorecem o crescimento, foram mencionadas como determinantes parcerias com outras instituições, corroborando estudos anteriores (Coad \& Tamvada, 2012; Davidsson et al., 2010). O efeito positivo da aglomeração (arranjo produtivo) foi mencionado pelas empresas do Estado do Paraná, e foi constatado anteriormente por Hoogstra e Kijk (2004). É importante destacar a relevância atribuída pelos participantes ao apoio de grandes empresas, não mencionado em estudos anteriores como determinante de crescimento. No conjunto das determinantes de crescimento, mencionadas pelos empreendedores nesta pesquisa, as determinantes: cooperação com grandes empresas, certificações e valorização do tempo de trabalho de funcionários não foram mencionadas em estudos anteriores e configuram especificidades do crescimento dessas empresas de software. A inovação foi mencionada como uma determinante de crescimento para eles, mas nenhuma das empresas mencionou a obtenção de patentes, importante para empresas de base tecnológica (Löfsten, 2016).

\section{Dificuldades para atingir o crescimento}

Para os empreendedores que participaram desta pesquisa, o crescimento no segmento que atuam apresenta como dificuldades: (a) demora no desenvolvimento do produto; (b) dificuldade relacionada à formação e contratação de pessoas; (c) concorrência com grandes empresas e; (d) cultura.

Quanto à demora para o desenvolvimento do produto, esse foi um problema inicial para uma das empresas. Depois da abertura, a empresa ampliou o portfólio de produtos e esse problema passou a ter menor impacto no crescimento, como ilustra o trecho:

"Nós, quando chegamos em 2006, criamos a empresa, nós só fomos vender o primeiro produto no mercado em 2008. Então, durante dois anos nós ficamos praticamente criando para ter a primeira receita em 2008. Em 2008 começamos a vender e, aí sim, aí nós percebemos que tínhamos só programadores, nós não tínhamos vendedores, não tínhamos financeiro, faltava tudo na empresa, ela só tinha um setor “(EA).

O trecho ilustra também a falta de preparo inicial, na medida em que foi longo o tempo para o desenvolvimento do produto, para essa empresa. Além disso, os dois empreendedores eram graduados em Ciência da Computação e tinham apenas o conhecimento técnico. O conhecimento e o aprendizado gerencial foram obtidos a partir da experiência no empreendimento, uma vez que eles não tinham experiência na gestão de outros empreendimentos, o que poderia contribuir para o crescimento da empresa de acordo com Barringer et al. (2005) e Davidsson et al. (2010).

No que se refere às dificuldades associadas à formação de pessoas, esta foi mencionada por todos empreendedores e pode ser observada no seguinte depoimento que foi selecionado por melhor evidenciar a dificuldade:

“Ameaça hoje ainda está na questão de pessoas. É, para crescer, você precisa de líderes e, infelizmente, a gente não consegue formar líderes tão rápido quanto a gente consegue formar programador...O meu

RAC, Rio de Janeiro, v. 22, n. 6, art. 1, pp. 817-840, novembro/dezembro, 2018, http://rac.anpad.org.br (cc) E 
pensamento depende de pessoas, não formo pessoas assim. É diferente de você ter uma fábrica onde você compra o dobro de equipamentos porque você tem um contrato novo, coloca o dobro de matéria prima que você usa e você produz o dobro porque você assinou um contrato que agora vai produzir o dobro. Eu não consigo fazer isso. Minha curva de aprendizado de pessoas demora e eu não consigo crescer dentro desta unidade, dentro deste segmento" (ED).

O trecho anterior ilustra a dificuldade no ritmo da produção, uma característica do setor, que não atinge um ritmo de produção em série apenas com a contratação de mais pessoas, pois precisa investir na formação dessas pessoas. A curva do aprendizado é longa e o resultado não é imediato. Estudos anteriores apontaram que a falta de pessoas qualificadas pode representar uma dificuldade para o crescimento de empresas de base tecnológica (Davidsson et al., 2010; Hermans et al., 2012). Esse empreendedor enfatizou também outro desafio, que consiste na necessidade de formar lideranças. Esse aspecto é importante para essas empresas, em razão da necessidade de fomentarem o trabalho em equipe para desenvolvimento de seus produtos e serviços.

Ainda no tocante aos recursos humanos, uma das empresas reclamou da dificuldade em encontrar pessoal com maior qualificação em um município pequeno onde a empresa se instalou, principalmente no início do negócio:

"Principalmente como a gente não teve muitos problemas financeiros, foi de mão de obra, então assim, várias vezes, acho que mais de 50 vezes, pensei em sair desta cidade. Porque assim o que acontece sabe, a formação aqui da região, muitos profissionais, mas imagina 15 anos atrás como era, as pessoas eram muito interioranas e como eu viajava e via o universo lá fora bombando, crescendo, eu não conseguia trazer isso, que tínhamos que melhorar " $(\mathrm{EF})$.

A dificuldade quanto à disponibilidade de recursos humanos foi mencionada por Coad e Tamvada (2012) e Schoonjans et al. (2013). Nesta pesquisa, apenas a empresa F fez menção a esta dificuldade e, assim mesmo, referindo-se ao passado. Isso mostra que esta não é, atualmente, uma restrição do ambiente para essas empresas promoverem o seu crescimento.

Uma das dificuldades de crescimento associada ao ambiente, mencionada nesta pesquisa, foi a pressão da concorrência no mercado, forçando essas empresas a reduzirem os preços praticados. Uma das entidades enfatizou a dificuldade em negociar com grandes empresas, na medida em que as forças entre elas e as grandes são desproporcionais, como evidencia o trecho:

"Nossa concorrência é muito forte né. Hoje nós trabalhamos praticamente com duas concorrências, que é a OOO que comprou a MMMM, que tinha comprado o FFFF. Começou com o FFFF, que é uma empresa alemã e foi comprada pela MMMM, que é uma empresa gigante dos Estados Unidos e tem produtos hoteleiros. Essa empresa, a gente compete aqui no Brasil com eles, e agora ela foi comprada pela OOO, que é uma das maiores empresas do mundo, acho que perde só para a MIMI. Então, a briga é muito grande. Aí nosso outro concorrente, que era do Rio de Janeiro, uma empresa familiar, houve uns problemas de saúde com o proprietário e ele acabou vendendo para a BEBE, que é uma empresa paranaense e agora a BEBE foi toda vendida para a TOTO. Então, assim, a gente está, é uma briga que eu diria, é do David e do Golias" (EF).

Do mesmo modo, Santos e Pinho (2010) identificaram a dificuldade de pequenas empresas de software em competirem com grandes empresas, tal como foi mencionado pelo empreendedor $\mathrm{F}$. No trecho mencionado, o empreendedor utiliza uma metáfora, referindo-se à briga dele como anão com os gigantes do setor.

Por fim, um dos participantes mencionou a cultura como uma dificuldade de crescimento. A cultura pode ser entendida como: "um sistema mais ou menos coeso de significados e símbolos, em termos dos quais as interações sociais tomam lugar" (Alvesson, 2007, p. 5). Para o empreendedor D, é importante uma cultura de resultados, que não é a vigente, como mostra o depoimento: 


\begin{abstract}
“O crescimento vai depender da cultura da empresa, é uma empresa pequena, eu preciso levar essa cultura do atendimento ao cliente, da importância que ele se sinta bem, desde o dono até quem está desenvolvendo uma arte, desenvolvendo alguma coisa que vai servir...uma questão de cultura, o brasileiro, falo de uma questão de resultado. Todo mundo tem que estar ciente de que a gente precisa de resultado, eu preciso do cliente satisfeito. Preciso que aquele produto que ele está fazendo tenha qualidade, resolva o cliente, não é uma coisa trivial, então essa cultura de resultados, esse entendimento que isso aqui vai ser bom para mim, se não fizer um trabalho de excelência vai comprometer o resultado, ...talvez seria essa cultura de resultado que a gente deveria trabalhar, desde a faculdade, desde casa, a gente deveria trabalhar”. (ED).
\end{abstract}

A cultura da empresa é uma condição que favorece o crescimento (Achtenhagen et al., 2010; Antoncic \& Antoncic, 2011; Gnyawali \& Byung-Jin, 2009). Para Apostolou e Mentzas (2003), as empresas do setor de software precisam inserir na cultura e na estratégia a criação e compartilhamento de conhecimento, sendo que isso dependerá também da estratégia da empresa em proporcionar o contato de seus colaboradores com informações e fontes externas e com pessoas de outras organizações. No entanto, não é sobre o aspecto do compartilhamento do conhecimento que o empreendedor D se refere, e sim à necessidade de uma cultura, que não apenas a organizacional, com maior racionalidade instrumental, voltada a resultados.

\title{
Determinantes e dificuldades de crescimento para pequenas empresas de base tecnológica
}

Para Wiklund et al. (2009), as determinantes de crescimento podem ser associadas ao indivíduo, à empresa e ao ambiente. De acordo com os dados desta pesquisa, as empresas de software mencionaram determinantes do crescimento associadas a ações nos três níveis.

Quanto ao indivíduo, é importante salientar que todos os participantes tinham experiência no setor ou em grandes empresas do setor, importante para o crescimento (Davidsson et al., 2010; Rauch \& Rijskik, 2013). Além dos aspectos citados na literatura, os resultados desta pesquisa mostraram que a participação do empreendedor no crescimento está associada à quantidade de horas dedicadas ao trabalho e à participação em Feiras. Eles não mencionaram a importância de contatos informais com outras empresas do setor, como identificaram Araújo e Garcia (2013), mas eles enfatizaram a importância de redes informacionais (consultores) e da Associação das Empresas de Software.

Em nível da empresa, os participantes da pesquisa mencionaram principalmente a inovação e os recursos humanos. Quanto à inovação, esta foi mencionada em produtos existentes e em novos produtos e em processos de vendas. Para essas empresas, estratégias de inovação estão associadas à diversificação de produtos a serem ofertados aos clientes, voltadas às necessidades dos clientes, sem, contudo, mencionarem patentes. Para Penrose (2006), a diversificação acompanha o crescimento de empresas e, para ela, a diversificação "inclui aumentos na variedade dos produtos finais gerados, acréscimos na integração vertical e aumentos no número de áreas básicas de produção que a firma atua" (p. 175). A diversificação para esses empreendedores de software caracteriza-se como uma diversificação dentro da mesma área de especialização, como se refere Penrose (2006), ou seja, "a produção de mais produtos baseados na mesma tecnologia e vendidos nos mercados existentes das firmas" (p. 177). Apenas uma das empresas participantes desta pesquisa apresentou tecnologia diferente no produto que está sendo desenvolvido em outra linguagem e somente uma das empresas mencionou a estratégia de focar em mercados existentes. As demais estão se organizando para ampliar seus mercados, quer seja em novas cidades, regiões ou países ou, ainda, para novos segmentos, que foram os casos das empresas D e F. Esse resultado corrobora com Davidsson et al. (2010), que afirmaram que, para empresas de base tecnológica, o crescimento pode ter o significado de diversificação e de combinação produto-mercado.

Outra determinante de crescimento em nível de empresa, segundo os empreendedores desta pesquisa, refere-se à gestão dos recursos humanos, abrangendo a seleção, a qualificação e incentivos e treinamentos. Por outro lado, a utilização de publicidade e promoções, relevante para o crescimento de empresas (Brush \& Hisrich, 1991), não foi mencionada nesta pesquisa. Da mesma forma, em geral, as empresas não mencionaram estratégias de internacionalização, que é uma determinante de crescimento (Achtenhagen et al., 2010; Coad \& Tamvada, 2012). Para a maioria das empresas desta pesquisa o mercado interno apresenta demanda suficiente para propiciar o crescimento. 
Como determinantes do crescimento associadas ao ambiente, os empreendedores citaram o apoio de outras instituições (SEBRAE, FINEP, BNDES, Universidades e grandes empresas) e a obtenção de certificações. As empresas apontaram a relevância de universidades locais, no entanto, observou-se que a relação com essas instituições limita-se à contratação de egressos, sem outras estratégias de transferência de tecnologia, o que seria importante para o crescimento dessas empresas (Hermans et al., 2012). Por meio de contatos, as empresas utilizam redes informacionais, que constituem fontes de informação novas. Essas redes "compreendem as consultorias, os organismos de formação, centros de pesquisa, diversos organismos governamentais e ajuda, entre outros" (Julien, 2010, p. 226).

Como dificuldades de crescimento as empresas enfatizaram: a demora para o desenvolvimento de produtos, a dificuldade no preparo da equipe, dificuldades em negociar e em competir com grandes empresas. Além disso, um dos participantes da pesquisa mencionou a necessidade de uma cultura voltada a resultados para propiciar o crescimento. As dificuldades de crescimento mencionadas pelos empreendedores, nesta pesquisa, referem-se à gestão e ao ambiente. Eles não mencionaram dificuldades associadas ao empreendedor, como mostraram estudos anteriores, tais como falta de formação gerencial ou de auto confiança (Fleck, Hegarty, \& Neergaard, 2011).

O crescimento é importante para sobrevivência de pequenos negócios (Coad, Frankish, Roberts, \& Storey, 2013). Para as empresas de software, como mostraram os resultados desta pesquisa, o crescimento é uma condição de sobrevivência, para enfrentar a competição, principalmente com grandes empresas. Em geral, empresas de base tecnológica apresentam elevado crescimento, mas no caso de pequenas e médias empresas, a trajetória de crescimento é diferente porque elas contam com menos recursos do que as grandes empresas. Com isso, elas precisam gerir o relacionamento com cliente e com parceiros (Eito-Brun \& Sicilia, 2017; Lasch et al., 2007). Simultaneamente, os empreendedores necessitam desenvolver continuamente a capacidade de inovação e de diversificação de produtos. Para isso, eles precisam preparar uma equipe interna e contar com o apoio de outras instituições.

\section{Considerações Finais}

Esta pesquisa investigou como empreendedores compreendem o processo de crescimento de empresas de software, focando dificuldades e determinantes de crescimento, o que é importante porque empreendedores têm um papel central no crescimento das empresas (Rasmussen et al., 2016).

De acordo com os resultados desta pesquisa, os empreendedores percebem o crescimento de seus empreendimentos como um processo que inclui ações deles, da gestão das empresas e do ambiente. Quanto às suas ações, eles mencionaram a importância da participação em Feiras, da dedicação intensa ao trabalho e do engajamento em redes como determinantes de crescimento. Em nível de gestão da empresa, mencionaram como determinantes de crescimento, principalmente estratégias e políticas de inovação e de recursos humanos, mas também a adoção de uma política financeira de reinvestimentos e a busca por certificações e consultorias. Em nível do ambiente, o apoio de outras instituições foi determinante para o crescimento, destacando-se universidades, grandes empresas, consultores e órgãos de fomento a pequenos negócios.

A percepção de dificuldades de crescimento limitou-se ao nível da empresa e do ambiente. Em nível da empresa, as dificuldades mencionadas foram: demora para o desenvolvimento de produtos, dificuldade no preparo da equipe, dificuldades em negociar e em competir com grandes empresas. Em nível de ambiente, a dificuldade foi a falta de uma cultura voltada a resultados.

Os resultados desta pesquisa mostraram uma visão processual do crescimento para pequenas e médias empresas de software, por meio de dificuldades e determinantes do crescimento. Convém salientar que o conhecimento de dificuldades específicas de crescimento, como as que foram mencionadas nesta pesquisa, não é suficiente para predizer o crescimento (Doern, 2009). Contudo, a percepção de dificuldades pode influenciar intenções de crescimento (Doern, 2011). Do mesmo modo, 
a percepção de determinantes de crescimento pode influenciar a formulação de estratégias por empreendedores. Com isso, os resultados desta pesquisa contribuem para evidenciar a importância do empreendedor para a compreensão do crescimento, em uma perspectiva processual.

A opção pelo método qualitativo de pesquisa foi importante para analisar o crescimento em uma perspectiva processual. Lasch et al. (2007) salientam a dificuldade em analisar simultaneamente grupos de fatores associados ao empreendedor, à empresa e ao ambiente socioeconômico. O método qualitativo favoreceu essa dimensão de análise, que é importante para evidenciar a multidimensionalidade do fenômeno do crescimento, dependente de ações gerenciais, ações dos empreendedores e do ambiente.

Como contribuição prática, esta pesquisa apresenta resultados que podem servir de subsídios para formulação de políticas de fomento a empresas do setor de software. Além disso, os resultados podem contribuir para futuros empreendedores, ao mostrar aspectos importantes associados ao crescimento das empresas desse setor.

Como limitação, ressalta-se que a pesquisa não abrangeu todas as etapas do processo de crescimento, focando apenas determinantes e dificuldades de crescimento. Estudos futuros podem investigar outros aspectos do processo de crescimento. Outra limitação é que o estudo não contou com empreendedores spin-offs de incubadoras, o que pode ser explorado em estudos futuros.

\section{Nota}

${ }^{1}$ Agência Financiadora - CNPq Processo 303330/2014-7.

\section{Material Suplementar}

Todos os dados e materiais foram disponibilizados publicamente por meio da plataforma Mendeley e podem ser acessados em: Pelizza Vier Machado, Hilka(2018), "Growth of Companies from the Perspective of Small Technology-Based Entrepreneurs”, Mendeley Data, v1 http://dx.doi.org/10.17632/h6n9kv4ymw.1DOI is reserved but not active

\section{Referências}

Achtenhagen, L., Naldi, L., \& Melin, L. (2010). Business growth - Do practitioners and scholars really talk about the same thing? Entrepreneurship Theory \& Practice, 34(2), 289-316. https://doi.org/10.1111/j.1540-6520.2010.00376.x

Alvesson, M. (2007). Understanding organizational culture. London: SAGE Publications

Antoncic, J. A., \& Antoncic, B. (2011). Employee satisfaction intrapreneurship and firm growth: A model. Industrial Management \& Data Systems, 111(4), 589-607. https://doi.org/10.1108/02635571111133560

Apostolou, D., \& Mentzas, G. (2003). Experiences from knowledge management implementations in companies of the software sector. Business Process Management Journal, 9(3), 354-381. https://doi.org/10.1108/14637150310477939

Araújo, V. de C., \& Garcia, R. (2013). Transbordamentos locais de conhecimento por meio de contatos informais: Uma análise a partir do sistema local de indústrias TIC de Campinas. Revista Brasileira de Inovação, 12(1), 105-132. https://doi.org/10.20396/rbi.v12i1.8649056 
Associação Brasileira de Empresas de Software. (2016). Mercado brasileiro de software: panorama e tendências. $\quad$ Recuperado http://central.abessoftware.com.br/Content/UploadedFiles/Arquivos/Dados\%202011/ABESPublicacao-Mercado-2016.pdf

Bardin, L. (2011). Análise de conteúdo. São Paulo: Edições 70.

Barringer, B. R., Jones, F. F., \& Neubaum, D. O. (2005). A quantitative content analysis of the characteristics of rapid growth firms and theirs founders. Journal of Business Venturing, 20(5), 663-687. https://doi.org/10.1016/j.jbusvent.2004.03.004

Bauer, M. W., \& Gaskell, G. (2007). Pesquisa qualitativa com texto, imagem e som (7a ed.). Petrópolis: Vozes.

Brito, E., P., Z., Brito, L. A. L., Porto, E., C., \& Szilagyi, M. E. (2010). A relação entre aglomeração produtiva e crescimento: A aplicação de um modelo multinível ao setor industrial paulista. Revista de Administração Contemporânea, 14(4), 615-632. Recuperado de http://www.scielo.br/pdf/rac/v14n4/04.pdf. http://doi.org/10.1590/S1415-65552010000400004

Brush, C. G. (1992). Research on women business owners: Past trends, a new perspective and future directions. Entrepreneurship Theory and Practice, 16(4), 5-26. https://doi.org/10.1177/104225879201600401

Brush, C. G., Ceru, D. J., \& Blackburn, R. (2009). Pathways to entrepreneurial growth: The influence of management, marketing, and money. Business Horizons, 52(5), 481-491. https://doi.org/10.1016/j.bushor.2009.05.003

Brush, C. G., \& Hisrich, R. D. (1991). Antecedent influences on women-owned businesses. Journal of Managerial Psychology, 6(2), 9-16. https://doi.org/10.1108/02683949110144846

Coad, A., Frankish, J., Roberts, R. G., \& Storey, D. J. (2013). Growth paths and survival chances: An application of Gambler's Ruin theory. Journal of Business Venturing, 28(5), 615-632. https://doi.org/10.1016/j.jbusvent.2012.06.002

Coad, A., \& Tamvada, J. P. (2012). Firm growth and barriers to growth among small firms in India. Small Business Economics, 39(2), 383-400. https://doi.org/10.1007/s11187-011-9318-7

Davidsson, P., Achtenhagen, L., \& Naldi, L. (2010). Small firm growth. Foundations and Trends in Entrepreneurship, 6(2), 69-166. https://doi.org/10.1561/0300000029

Denzin, Y. S., \& Lincoln (Eds.). (2001). Handbook of qualitative research. Thousand Oaks: Sage.

Dobbs, M., \& Hamilton, R. T. (2007). Small business growth: Recent evidence and new directions. International Journal of Entrepreneurship Behavior and Research, 13(5), 296-322. https://doi.org/10.1108/13552550710780885

Doern, R. (2009). Investigating barriers to SME growth and development in transition environments. International Small Business Journal, 27(3), 275-305. https://doi.org/10.1177/0266242609102275

Doern, R. (2011). Understanding how perceived barriers influence growth intentions and behaviours. International Journal of Entrepreneurial Behaviour \& Research, 17(5), 488-514. https://doi.org/10.1108/13552551111158826

Downing, S. (2005). The social construction of entrepreneurship: Narrative and dramatic processes in the coproduction of organization and identities. Entrepreneurship Theory \& Practice, 29(2), 185 204. https://doi.org/10.1111/j.1540-6520.2005.00076.x 
Eisenhardt, K. M. (1989). Building theories from case study research. Academy of Management Review, 14(4), 532-550. https://doi.org/10.2307/258557

Eito-Brun, R., \& Sicilia, M.-A. (2017). An innovation activity model for very small entities in the software sector: An empirical study. $R \quad \& \quad D$ Management, 47(5), E13-E25. https://doi.org/10.1111/radm.12226

Fleck, E., Hegarty, C., \& Neergaard, H. (2011). The politics of gendered growth. International Journal of Gender and Entrepreneurship, 3(2), 164-173. https://doi.org/10.1108/17566261111140224

Gibbs, G. (2009). Análise de dados qualitativos. Porto Alegre: ArtMed.

Gnyawali, D. R., \& Byung-Jin, R. P. (2009). Co-opetition and technological innovation in small and medium-sized enterprises: A multilevel conceptual model. Journal of Small Business Management, 47(3), 308-330. https://doi.org/10.1111/j.1540-627X.2009.00273.x

Gussoni, W. M. da S., Weise, A. D., \& Medeiros, F. S. B. (2015). Cooperação e governança nos arranjos produtivos locais: O caso das empresas de software no Estado do Paraná. Desenvolvimento em Questão, 13(29), 125-157. https://doi.org/10.21527/2237-6453.2015.29.125-157

Hamilton, R. T. (2012). How firms grow and the influence of size and age. International Small Business Journal, 30(6), 611-621. https://doi.org/10.1177/0266242610383446

Hermans, J., Vanderstraeten, J., Dejardin, M., Ramdani, D., Stam, E., \& Witteloostuijn, A. van (2012). Ambitious entrepreneurship: Antecedents and consequences (Working Paper $n^{\circ}$ 2012-023). University of Antwerp, Faculty of Applied Economics, Antwerp, Belgica.

Hoogstra, G. J, \& Djik, J. van (2004). Explaining firm employment growth: Does location matter? Small Business Economics, 22(3/4), 179-192. https://doi.org/10.1023/B:SBEJ.0000022218.66156.ac

Houghton, C. E., Murphy, K., Meehan, B., Thomas, J., Brooker, D. J. R., \& Casey, D. (2016). From screening to synthesis: Using NVIVO to enhance transparency in qualitative evidence synthesis. Journal of Clinical Nursing, 26(5/6), 873-881. https://doi.org/10.1111/jocn.13443

Janssen, F. (2009). The conceptualization of growth: Are employment and turnover interchangeable $\begin{array}{llll}\text { criteria? } \quad \text { Journal } & \text { 21-45. }\end{array}$ https://doi.org/10.1177/097135570801800102

Julien, P. A. (2010). Empreendedorismo regional e economia do conhecimento. São Paulo: Saraiva.

Kirk, H., \& Miller, M. (1986). Reliability and validity in qualitative research. London: Sage.

Lasch, F., Le Roy, F., \& Yami, S. (2007). Critical growth factors of ICT start-ups. Management Decision, 45(1), 62-75. https://doi.org/10.1108/00251740710718962

Leech, N. L., \& Onwuegbuzie, A. J. (2011). Beyond constant comparison qualitative data analysis: Using N Vivo. School Psychology Quarterly, 26(1), 70-84. https://doi.org/10.1037/a0022711

Leitch, C. M., Hill, F. M., \& Harrison, R. T. (2010). The philosophy and practice of interpretativist research in entrepreneurship: Quality, validation and trust. Organizational Research Methods, 13(1), 67-84. https://doi.org/10.1177/1094428109339839

Levie, J., \& Lichtenstein, B. B. (2010). A terminal assessment of stages theory: Introducing a dynamic states approach to entrepreneurship. Entrepreneurship Theory \& Practice, 34(2), 317-350. https://doi.org/10.1111/j.1540-6520.2010.00377.x

Löfsten, H. (2016). Business and innovation resources: Determinants for the survival of new technologybased firms. Management Decision, 54(1), 88-106. https://doi.org/10.1108/MD-04-2015-0139 
Lumpkin, G. T., \& Dess, G. G. (1996). Clarifying the entrepreneurial orientation construct and linking it to performance. Academy of Management Review, 21(1), 135-172. http://doi.org/10.2307/258632

McKelvie, A., \& Wiklund, J. (2010). Advancing firm growth research: A focus on growth mode instead of growth rate. Entrepreneurship Theory \& Practice, 34(2), 261-288. https://doi.org/10.1111/j.1540-6520.2010.00375.x

Moreno, A. M., \& Casillas, J. C. (2008). Entrepreneurial orientation and growth of SMEs: A causal model. Entrepreneurship Theory and Practice, 32(3), 507-528. https://doi.org/10.1111/j.15406520.2008.00238.x

Moretti, S. L. do A., \& Crnkovic, L. H. (2015). Fatores estruturais e aspectos recursivos no desenvolvimento de pequenas empresas de base tecnológica, em São Carlos, SP: Um estudo sob a ótica da teoria da estruturação de Giddens. Revista Gestão \& Tecnologia, 15(1), 5-31. https://doi.org/10.20397/2177-6652/2015.v15i1.681

Organisation for Economic Co-operation and Development. (1998). Small businesses, job creation and growth: Facts, obstacles and best practices. Brasília: Autor.

Organisation for Economic Co-operation and Development e Financiadora de Estudos e Projetos. (1997). Manual de Oslo - Diretrizes para coleta e interpretação de dados sobre inovação (3a ed.). Brasília: Autor.

Orser, B., J., Riding, A., L., \& Manley (2006). Women entrepreneurs and financial capital. Entrepreneurship Theory and Practice, 30(5), 643-665. https://doi.org/10.1111/j.15406520.2006.00140.x

Penrose, E. (2006). A teoria do crescimento da firma. Campinas: Editora da Unicamp.

Rannikko, H. (2012). Early development of new technology-based firms. A longitudinal analysis on new technology-based firms' development from population level and firm level perspectives. economics and society (Thesis). Department of Management and Organization, Hanken School of Economics, Helsinki, Finland.

Rasmussen, C. C., Ladergard, G., \& Korhnone-Sande, S. (2016). Growth intentions and board composition in high-growth firms. Journal of Small Business Management, 56(4), 601-617. https://doi.org/10.1111/jsbm.12307

Rauch, A., \& Rijskik, S. A. (2013). The effects of general and specific human capital on long-term growth and failure of newly founded businesses. Entrepreneurship Theory \& Practice, 37(4), 923-941. https://doi.org/10.1111/j.1540-6520.2011.00487.x

Reid, G. C., \& Xu, Z. (2012). Generalizing gibrat: Using Chinese evidence founded on fieldwork. Small Business Economics, 39(4), 1017-1028. https://doi.org/10.1007/s11187-011-9338-3

Sampieri, R., H., Collado, C., F., Lucio, M., P., \& Baptista, M. (2013). Metodologia de Pesquisa (5a ed.). Porto Alegre: Penso.

Santos, D. T., \& Pinho, M. (2010). Análise do crescimento das empresas de base tecnológica no Brasil. Produção, 20(2), 214-223.

Sarwoko, E., \& Frisdiantara, C. (2016). Growth determinants of small medium enterprises (SMEs). Universal Journal of Management, 4(1), 36-41. https://doi.org/10.13189/ujm.2016.040105

Schoonjans, B., Van Cauwenberge, P., \& Bauwhede, H. V. (2013). Formal business networking and SME growth. Small Business Economics, 41(1), 169-181. https://doi.org/10.1007/s11187-0119408-6 
Stam, E., \& Wennberg, K. (2009). The roles of R \& D in new firm growth. Small Business Economics, 33(1), 77-89. https://doi.org/10.1007/s11187-009-9183-9

Storey, D. J. (1994). Understanding the small business sector. London, Boston: International Thomson Business Press.

Teruel-Carrizosa, M. (2010). Gibrat's law and the learning process. Small Business Economics, 34(4), 355-373. https://doi.org/10.1007/s11187-008-9127-9

Tumelero, C., Marins, C., Santos, S. A., \& Carnaúba, A. C. (2015). Estudo do conhecimento em pequenas empresas de base tecnológica incubadas. Revista de Gestão de Tecnologia, 11(1), 1-15.

Wiklund, J., Patzelt, H., \& Shepherd, D. A. (2009). Building an integrative model of small business growth. Small Business Economics, 32(4), 351-374. https://doi.org/10.1007/s11187-007-9084-8

Wright, M., \& Stigliani, I. (2012). Entrepreneurship and growth. International Small Business Journal. 31(1), 3-22. https://doi.org/10.1177/0266242612467359

Zampetakis, L., Bakatsaki, M., Kafetsios, K., \& Moustakis, V. S. (2016). Sex differences in entrepreneur's business growth intentions: An identity approach. Journal of Innovation and Entrepreneurship, 5(29), 1-20. https://doi.org/10.1186/s13731-016-0057-5

\section{Autor}

Hilka Pelizza Vier Machado

Av. Nereu Ramos, D - 3777, Seminário, 89813-000, Chapecó, SC, Brasil.

E-mail: hilkavier@yahoo.com 